International Journal of Distributed and Parallel Systems (IJDPS) Vol.3, No.3, May 2012

\title{
Evaluation of various Traffic loads in MANET with DSR routing protocol through use of OPNET Simulator
}

\author{
Parulpreet Singh ${ }^{1,}$ Ekta Barkhodia ${ }^{2}$, Gurleen Kaur \\ Walia $^{3}$ \\ ${ }^{1,2}$ Department of Electronics \& Communication, LPU, \\ Phagwara Punjab, India \\ Parulpreet89@gmail.com, ektabo@gmail.com
}

\begin{abstract}
Mobile Ad-hoc Network (MANET) is a collection of wireless mobile nodes dynamically forming a temporary network without the aid of any established infrastructure or centralized administration. The mobility of nodes in MANETs results in frequent changes of network topology making routing in MANETs a challenging task. Routing protocols in MANET helps node to send and receive packets. Some studies have been

reported in the literature to evaluate the performance of the proposed routing algorithms. This paper evaluates the performance of reactive (DSR) routing protocols in MANETs based on Average end-to-end delay, Throughput using OPNET 14.5. The performance DSR routing protocols is evaluated with respect to throughput and end-to-end delay under different traffic load using OPNET simulator.
\end{abstract}

KEYWORDS - MANET, DSR, Http, FTP, E-mail, OPNET.

\section{INTRODUCTION}

A Mobile Ad-hoc Network (MANET) is a set of wireless mobile nodes forming a dynamic autonomous network. Nodes communicate with each other without the intervention of centralized access points or base stations. In such a network, each node acts both as a router and as a host. Due to the limited transmission range of wireless network interfaces, multiple hops are needed to exchange data between nodes in the network.

Mobile Ad hoc Network is the rapid growing technology from the past 20 years. The gain in their popularity is because of the ease of deployment, infrastructure less and their dynamic nature. MANETs created a new set of demands to be implemented and to provide efficient better end to end communication. The Dynamic Source Routing (DSR) Protocol is a sourcerouted on-demand routing protocol [1]. A node maintains route caches containing the source routes that it is aware of. The node updates entries in the route cache when it learns about new routes. In its packet head, each given routing packet has a complete and ordered node list which the packet will pass inevitably.

\section{DSR ROUTNG PROTOCOL}

DSR- Dynamic source routing protocol abbreviated as DSR is also a reactive protocol. The Dynamic Source Routing (DSR) [10], [11] is one of the purest examples of an on-demand routing protocol that is based on the concept of source routing. DSR used to updates its route caches by finding new routes. It updates its cache with new route discovered or when there exist a direct route between source and destination node. When a node wants to transmit data, it defines a route for the transmission and then starts transmitting data through the defined route. In the DSR protocol, source node sends the routing request (RREQ) packets by means of 
flooding technology. Each RREQ packet includes source node address (Sid), destination node address (Did) and the unique request sequence-number (Request ID). An advantage of DSR is that nodes can store multiple routes in their route cache, which means that the source node can check its route cache for a valid route before initiating route discovery, and if a valid route is found there is no need for route discovery. This is very beneficial in network with low mobility. Since they routes stored in the route cache will be valid longer. Another advantage of DSR is that it does not require any periodic beaconing (or hello message exchanges), therefore nodes can enter sleep node to conserve their power. This also saves a considerable amount of bandwidth in the network.

There are two processes for route discovery and maintenance which are described below.

1. Route discovery process in DSR- When a source node wants to start data transmission with a node in the network, it checks its routing cache. When there is no route available to the destination in its cache or route is expired, it broad cast RREQ. When destination is located or any intermediate node that has fresh enough route to the destination node, RREP is generated [2]. When the source node receives the RREP it updates its caches and the traffic is routed through the route.

2. Route maintenance in DSR- When the transmission of data started, it is the responsibility of the node that is transmitting data to confirm the next hop received the data along with source route. The node generates a route error message, if it does not receive any confirmation to the originator node. The originator node again performs new route discovery process.

HTTP- In the simulation environment of HTTP traffic effect evaluation, scenarios have been implemented separately on HTTP heavy traffic load. HTTP traffic has been selected because of its importance in the Internet applications. It has been used with Web to provide secure communication. The simulation attempts to show the effect of HTTP traffic load on the routing protocols. It is assumed that the network includes 40 nodes with speed of $10 \mathrm{~m} / \mathrm{s}$. For each investigated scenarios, the performance parameters throughput and delay have been computed and tabulated as shown in Table.

E-MAIL- In the simulation environment of E-MAIL traffic effect evaluation, scenarios have been implemented separately on E-MAIL heavy traffic load. E-MAIL traffic has been selected because of its importance in the Internet applications and to send messages by mail. The simulation attempts to show the effect of E-MAIL traffic load on the routing protocols. It is assumed that the network includes 40 nodes with speed of $10 \mathrm{~m} / \mathrm{s}$. For each investigated scenarios, the performance parameters throughput and delay have been computed and tabulated as shown in Table.

VIDEO CONFERENCING- In the simulation environment of Video conf. traffic effect evaluation, scenarios has been implemented separately on Video conf. heavy traffic load.

\section{RELATED WORK}

Several researchers have done the qualitative and quantitative analysis of Ad-hoc Routing Protocols by means of different performance metrics. They have used different simulators for this purpose.

The results given in [3] analyze DSR and DSDV in idealized and realistic simulation environments on their performance. Another paper in reference [4] gives conclusion in mobile ad hoc network that reactive protocols i.e. AODV and DSR perform well when the network load is moderate. In reference [4] the reactive protocols are saving many resources like energy 
and bandwidth. It analyze that the proactive protocols perform well in heavy network traffic load. In reference [6], the simulation was done in QUALNET simulator. The author wrote that AODV shows best performance in low and medium node density but in high node density both OLSR and DSR outperforms. The author wrote that DSR is selected for file transfers where delivery and throughput are critical factors. Juan-Carlos Cano and Pietro Manzoni [7] concentrated on the energy consumption issues of routing protocols. They presented a performance comparison of the DSR, AODV, TORA and DSDV routing protocols with respect to energy consumption. Ehsan and Uzmi [8], presented the performance comparison of DSDV, AODV, DSR and TORA based on simulations performed using network simulator-2. Three metrics: normalized routing overhead, packet delivery fraction and average end to end delay, were used to measure performance. Karthikeyan et al. [9] studied the Reactive protocols, DSR and AODV as well as a Proactive Protocol, DSDV and their characteristics with respect to different mobility were analyzed based on packet delivery fraction, routing load, end to- end delay, number of packets dropped, throughput and jitter using Network Simulator (ns-2).

\section{SIMLATION TOOL}

This research is conducted using discrete event simulation software known as OPNET Modeler, which is just one of several tools provided from the OPNET Technologies suite. In order to undertake the experimental evaluation, the most recently available version, namely the OPNET Modeler 14.5 has been adopted in our study [5]. OPNET is one of the most extensively used commercial simulators based on Microsoft Windows platform, which incorporates most of the MANET routing parameters compared to other commercial simulators available.

The network entities used during the design of the network model are wireless server, application configuration, profile configuration, mobility configuration and workstations (nodes). The parameters that have been used in the following experiments are summarized in Table I.

Table 1. Simulation Parameter

\begin{tabular}{|c|c|}
\hline Simulation parameter & value \\
\hline Simulator & OPNET 14.5 \\
\hline Area & $800 \times 800(\mathrm{~m})$ \\
\hline Network Size & 35 nodes \\
\hline Mobility Model & Random way point \\
\hline Traffic type & $\begin{array}{c}\text { HTTP, FTP, } \\
\text { Email, VIDEO } \\
\text { CONFERENCING }\end{array}$ \\
\hline Simulation Time & 300 sec \\
\hline $\begin{array}{c}\text { Address mode } \\
\text { IPv4 }\end{array}$ \\
\hline $\begin{array}{c}\text { Packet Reception power } \\
\text { threshold }\end{array}$ & -95 \\
\hline
\end{tabular}




\section{PERFORMANCE METRICS}

End-to-End Delay: - The end-to-end delay is the time needed to traverse from the source node to the destination node in a network. End-to-end delay assesses the ability of the routing protocols in terms of use- efficiency of the network resources.

Throughput: - The average rate at which the data packet is delivered successfully from one node to another over a communication network is known as throughput. The throughput is usually measured in bits per second (bits/sec). A throughput with a higher value is more often an absolute choice in every network. Mathematically, throughput can be defined by the following formula.

Throughput $=($ number of delivered packet $*$ packet size $) /$ total duration of simulation

\section{SIMULATION RESULT AND ANALYSIS}

A network size of 35 nodes and the file size of 50,000 bytes (for HTTP) in a $(800 \times 800)$ square meter area.

This paper represent the scenarios of 35 nodes which are simulated by taking Reactive routing protocols DSR and showing graphically their delay, throughput. The simulation time is 300 seconds for all cases.

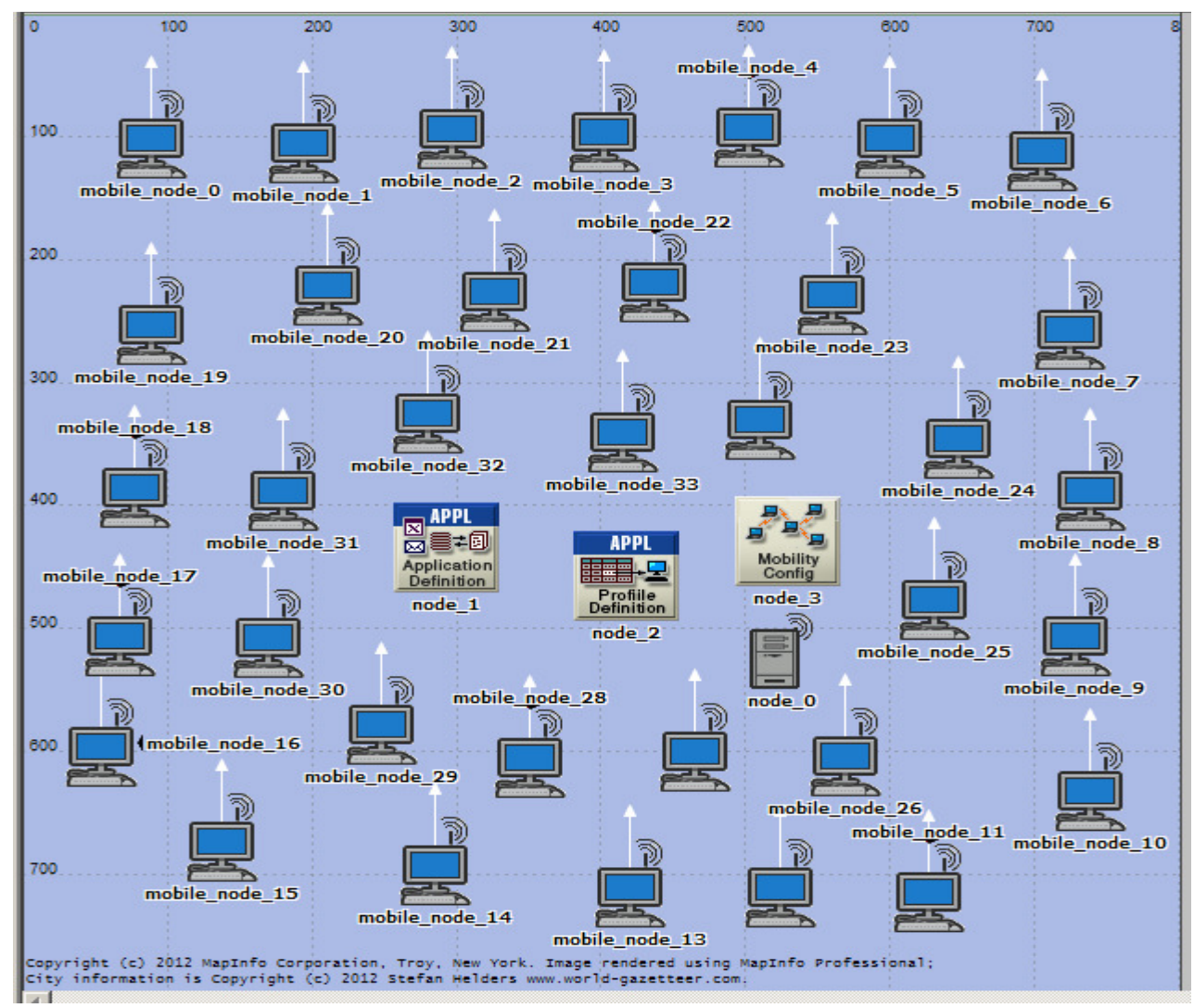

Figure 1- Simulation scenario having 35 nodes 
International Journal of Distributed and Parallel Systems (IJDPS) Vol.3, No.3, May 2012

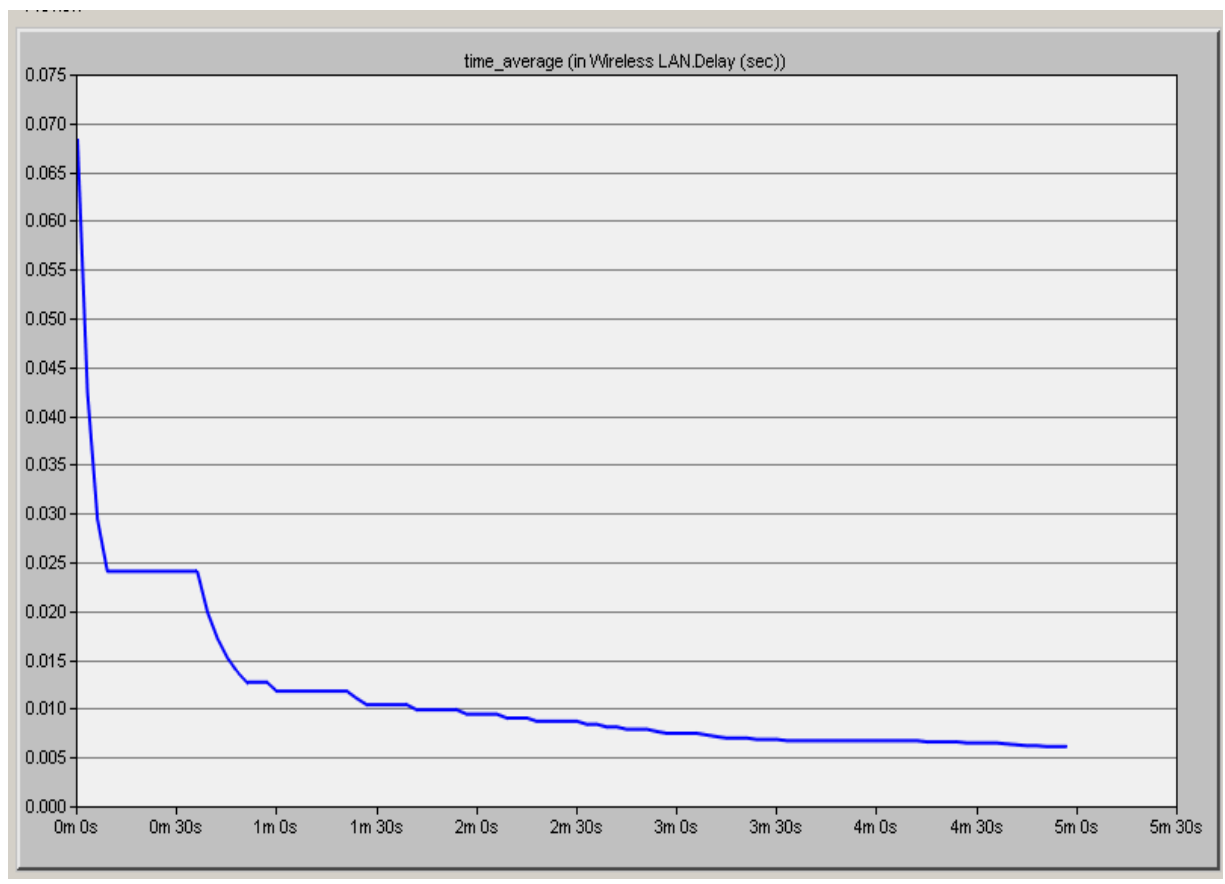

Figure 2- Average end to end delay with FTP load

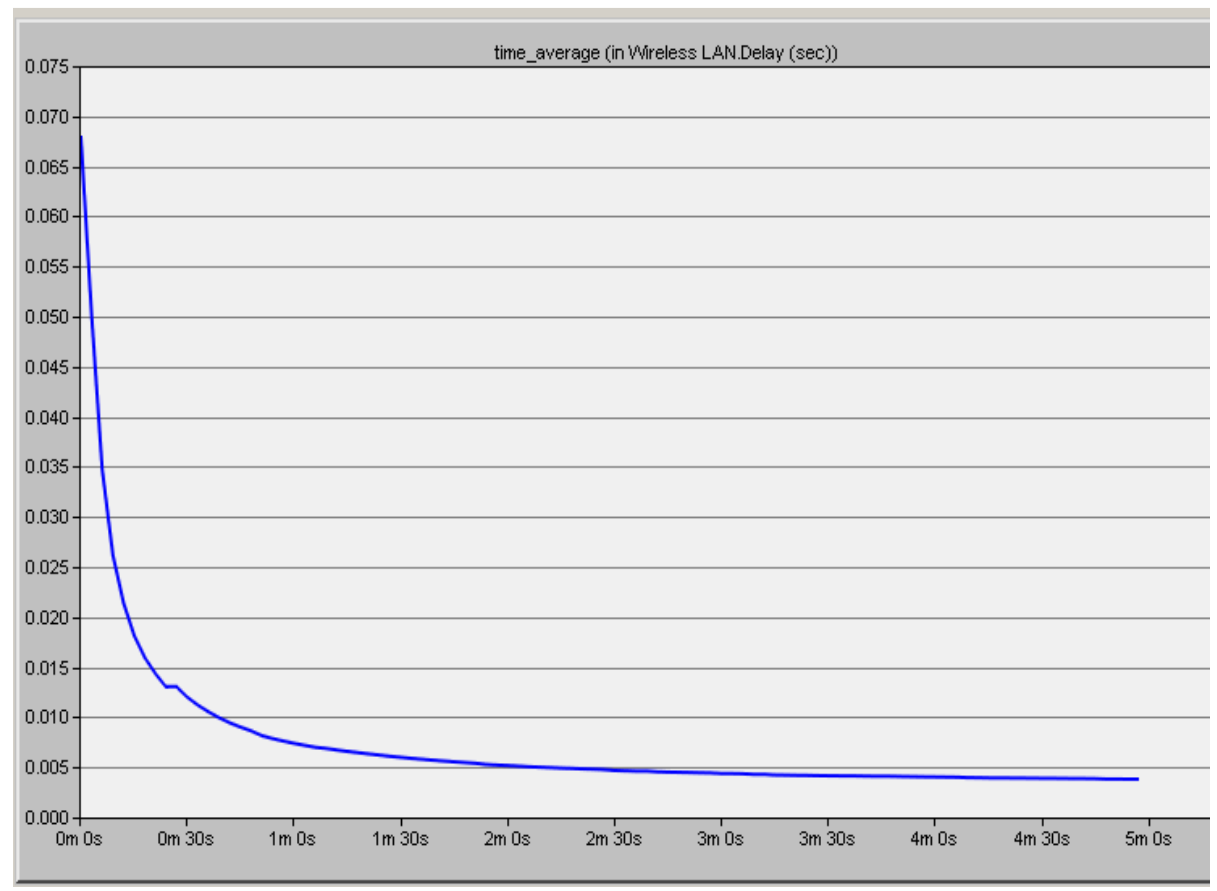

Figure 3- Average end to end delay with HTTP load

In the figure 3 shown the average end to end delays of HTTP. As compare to FTP , Http have low delay. 
International Journal of Distributed and Parallel Systems (IJDPS) Vol.3, No.3, May 2012

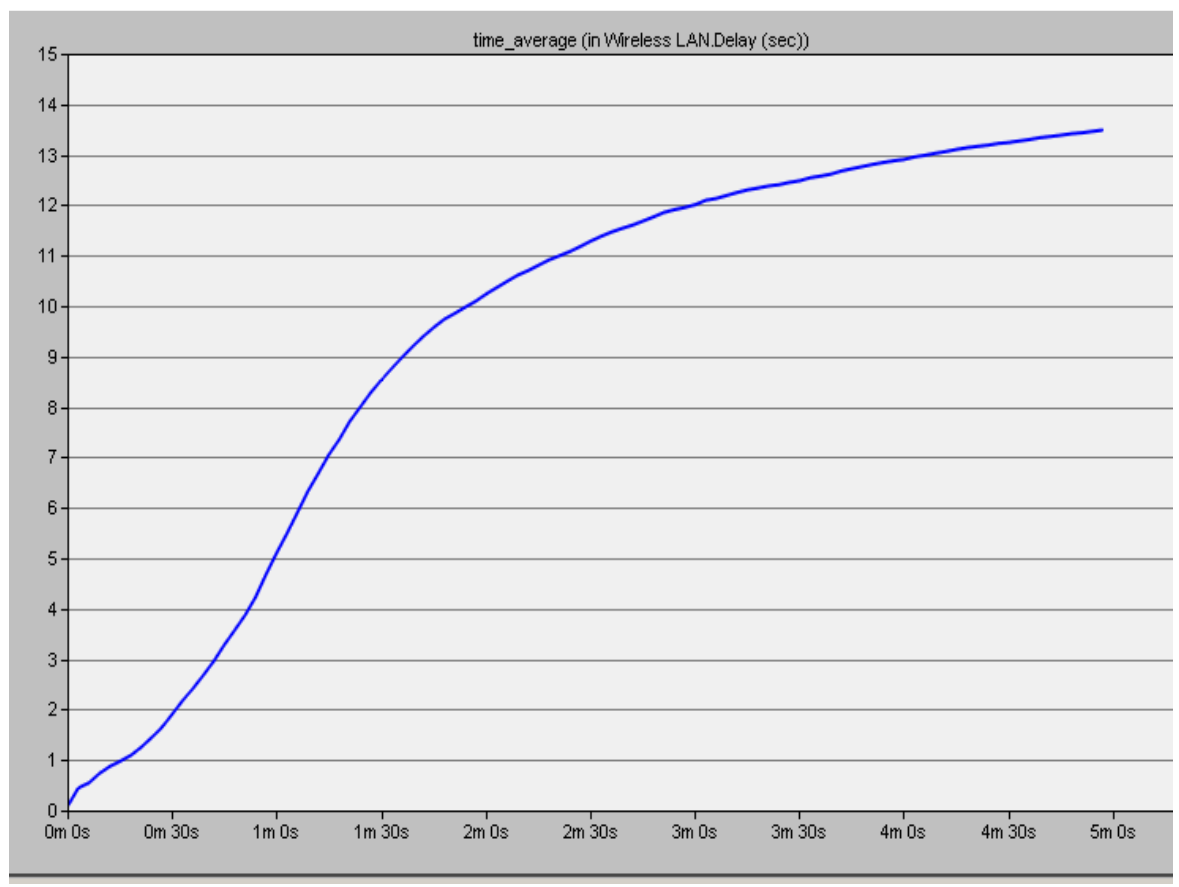

Figure 4- Average end to end delay with load video conferencing

In the figure 4 shows the highest average end to end delay with load video conferencing.

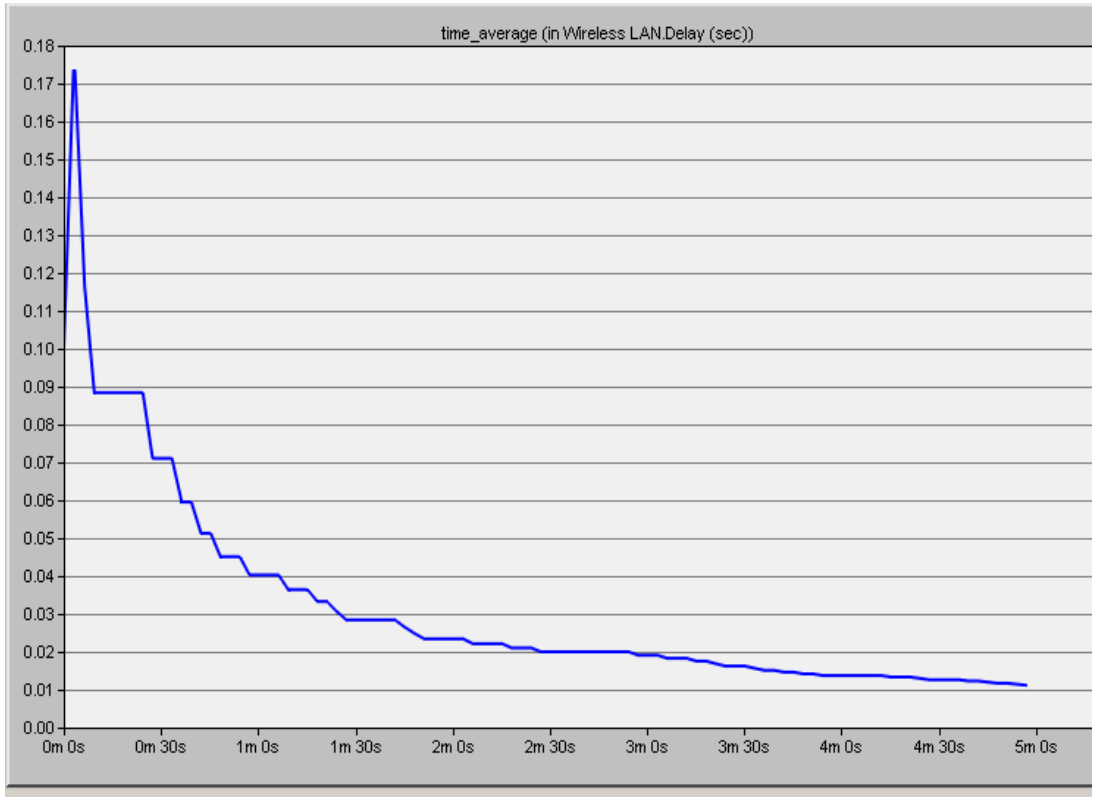

Figure 5- Average end to end delay with Email 
International Journal of Distributed and Parallel Systems (IJDPS) Vol.3, No.3, May 2012

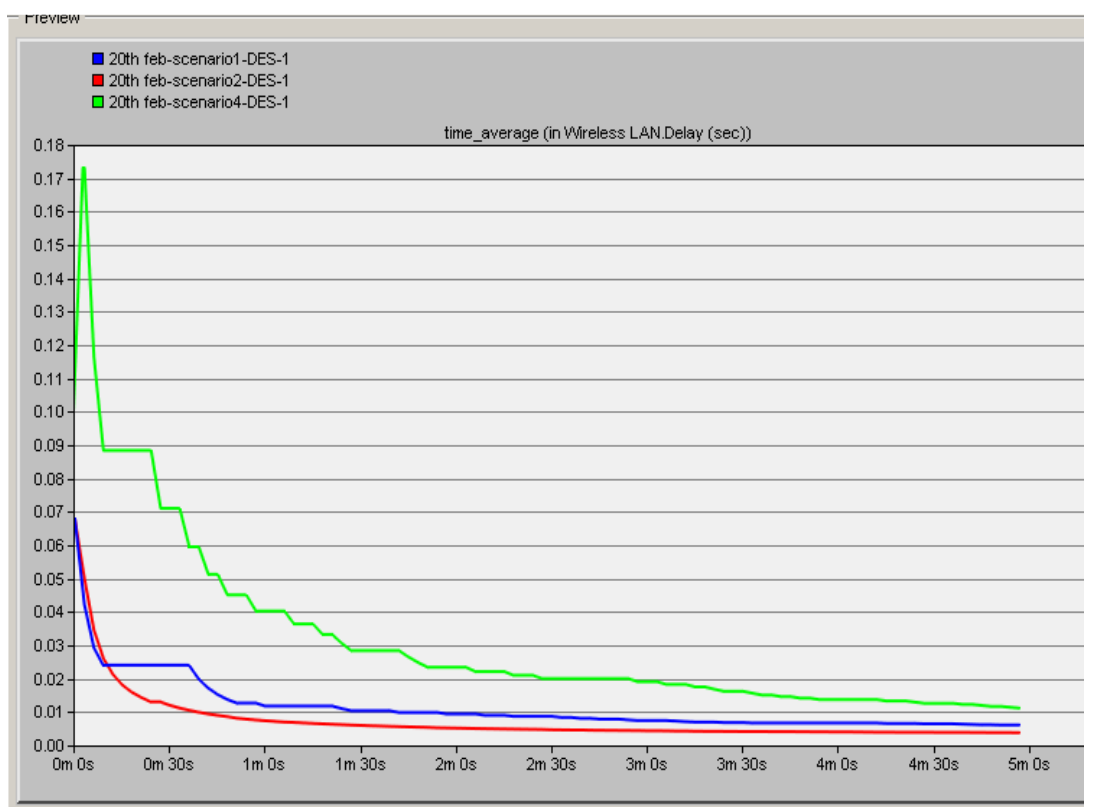

Figure 6- Average end to end delay comparison of HTTP, FTP, Email

As shown in the figure 6 end to end delay is highest in video conf. and lowest in HTTP and FTP case.

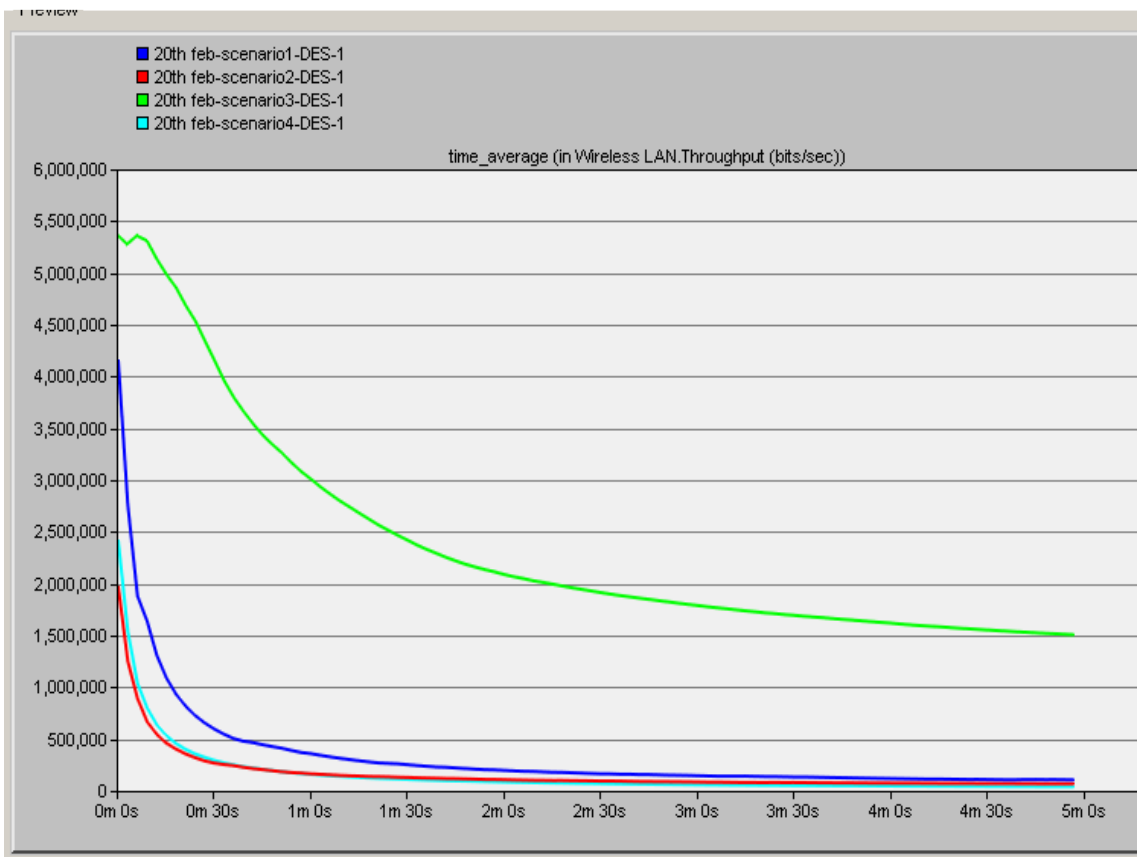

Figure 7- Throughputs of FTP, HTTP, EMAIL, video conf.

As shown in the figure 7 Throughput is highest in case of video conf. and lowest in case of HTTP. 


\section{CONCLUSION}

The key observations of the research are as follows.

DSR is based on source routing. One advantage with source routing approach is however that in its route discovery process, it learns more routes. In this paper the performance of DSR routing protocol is made under different traffic load like HTTP, FTP, Email, video conf at fix mobility $10 \mathrm{~m} / \mathrm{sec}$. From the observation average end to end delay is highest in video conf while lowest in HTTP. Throughput is also highest in Video conf and lowest in HTTP. In all our results, HTTP shows the best performance in terms of throughput and end-to-end delay. For the future work we can vary the node size. The network load is selected for the smaller size like 40 nodes and larger size like 90 nodes. We can compare the results with proactive protocols like OLSR and get the simulation results.

Table 2- Resultant value

\begin{tabular}{|c|c|c|c|c|}
\hline Load & $\begin{array}{c}\text { Mobility } \\
(\mathbf{m} / \mathbf{s e c})\end{array}$ & Type & Delay (sec) & $\begin{array}{c}\text { Throughput } \\
\text { (bits/sec) }\end{array}$ \\
\hline FTP & 10 & High load & 0.069 & $4.2 \times 10^{6}$ \\
\hline HTTP & 10 & High browsing & 0.068 & $1.97 \times 10^{6}$ \\
\hline Video Conf & 10 & High load & 13.5 & $5.4 \times 10^{6}$ \\
\hline Email & 10 & High load & 0.175 & $2.45 \times 10^{6}$ \\
\hline
\end{tabular}

\section{Acknowledgement}

The authors would like to thank OPNET for modeling tool support through their OPNET University Program.

\section{REFERENCES}

[1] Johnson David B, Maltz David A, Hu Yih-Chun.The Dynamic Source Routing for Mobile Ad Hoc Networks [DB/OL].ftp://ftp.rfceditor.org/in-notes/rfc4728.txt,2007.2/2008.1

[2] Zhu, C. Lee, M.J.Saadawi, T., "RTT-Based Optimal Waiting time for Best Route Selection in Ad hoc Routing Protocols," IEEE Military Communications Conference, Vol. 2, pp. 1054-1059, Oct, 2003.

[3] Amr M. Hassain, MohamedI. Youssef, Mohamed M. Zahra, "Evaluation of Ad Hoc Routing Protocols in Real Simulation Environments', Electronics and Electrical Communications Department, Faculty of Engineering, AL-AZHAR University Cairo, Egypt.

[4] F. Bertocchi, P. Bergamo, G. Mazzini, M. Zorzi, “Performance Comparison of Routing Protocols for Ad Hoc Networks", DI, University of Ferrara, Italy

[5] Opnet Technologies, Inc. "Opnet Simulator," Internet: www.opnet.com, date last viewed: 2010-0505

[6] Md. Anisur Rahman, Md. Shohidul Islam, Alex Talevski, “Performance Measurement of Various Routing Protocols in Ad-hoc Network'.

[7] Juan-Carlos Cano and Pietro Manzoni, “A Performance Comparison of Energy Consumption for Mobile Ad-hoc Network Routing Protocols",IEEE Transaction, 2000.

[8] Humaira Ehsan and Zartash Afzal Uzmi, "Performance Comparison of Ad-hoc Wireless Network Routing Protocols", IEEE Transactions, 2004.

[9] N. Karthikeyan, V. Palanisamy And K. Duraiswamy, "A Performance Evaluation Of Proactive And Reactive Protocols Using ns-2 Simulation”, International J. of Engg. Research \& Indu. Appls. (IJERIA).ISSN 0974-1518, Vol.2, No.II (2009), pp 309-326.

[10] M. Rajput, P. Khatri, A. Shastri and K. Solanki, "Comparison of Adhoc Reactive Routing Protocols using OPNET Modeler,” IEEE Proceedings 2010. 
[11] A. K. Gupta, H. Sadawarti and A. K. Verma, "Performance Analysis of AODV, DSR \& TORA Routing Protocols," IACSIT International Journal of Engineering and Technology, Vol.2, No.2, April 2010.

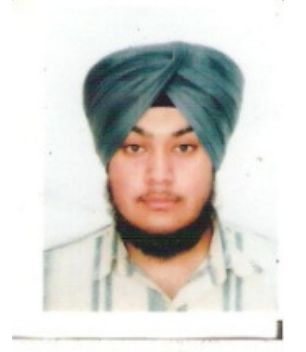

Parulpreet Singh received his Bachelor's degree in Electronics from CEM, Kapurthala, India. Now, he is pursuing his M.Tech degree in Electronics and communication from Lovely Professional University, Phagwara, Punjab, India. His areas of interest are MANET and Wireless Network.

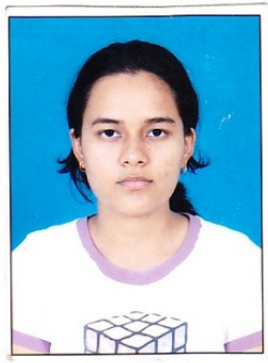

Ekta Barkhodia received her Bachelor's degree in Electronics from BRCM College of engineering and technology, Haryana, India. Now, she is pursuing her M.Tech degree in Electronics and communication from Lovely Professional University, Phagwara, Punjab, India. Her areas of interest are MANET and Wireless Network. 